\title{
Genetic Transformation Protocol for Early Flowering Cryptochrome Gene in Taif Rose Plant
}

\author{
Adel E.EL-Tarras ${ }^{1,2^{*}}$, Salah El-Asaal ${ }^{2}$ and Ahmed shahaby ${ }^{1,3}$ \\ ${ }^{1}$ Biotechnology and Genetic Engineering Unit, Scientific Research Deanship, \\ Taif University, KSA \\ ${ }^{2}$ Department of Genetics, Faculty of Agriculture, Cairo University, Cairo, Egypt \\ ${ }^{3}$ Department of Microbiology, Faculty of Agriculture, Cairo University, Cairo, Egypt \\ *Corresponding author
}

\begin{tabular}{|c|c|}
\hline & A B S T R A C T \\
\hline & Taif is one of the oldest cities in the world. It is located in the western part of Saudi \\
\hline $\begin{array}{l}\text { Ke y w o r d s } \\
\text { Biotechnology, } \\
\text { rose, cryptochrome, } \\
\text { genetic } \\
\text { transformation, } \\
\text { GUS. }\end{array}$ & $\begin{array}{l}\text { Arabia, Taif rose is considered as one of the most important economic products of Taif } \\
\text { governorate, KSA. The major use of Damask rose is distillation of petals in order to extract } \\
\text { its essential oil and producing rosewater. Due to the heterozygsity, high degree of sterility } \\
\text { and difficulty of breeding programs in Roses, therefore, the genetic transfer is the } \\
\text { appropriate way to increase productivity and improve quality. In the present study genetic } \\
\text { transformation in rose depend on tissue culture and gene transfer programmers, The stem } \\
\text { nods of the Taif-Rose genotype were used for the development of micropropagation }\end{array}$ \\
\hline Article Info & $\begin{array}{l}\text { system., the Arabidopsis natural early flowering time allele cape verde island (Cvi) of } \\
\text { cryptochrome } 2(\operatorname{ArCRY2}-\mathrm{Cm}) \text { gene was used for rose transformation in an attempt to }\end{array}$ \\
\hline $\begin{array}{l}\text { Accepted: } \\
\text { 20 February } 2017 \\
\text { Available Online: } \\
10 \text { March } 2017\end{array}$ & $\begin{array}{l}\text { produce early flowering transgenic rose. The reporter gene, GUS, was used for } \\
\text { determining transformation efficiency in this study. GUS was carried on several plasmid } \\
\text { constructs which also contained antibiotic resistance (kanamycin or streptomycin. } \\
\text { Efficiency of gene transfer was determined by calculating the number of transiently } \\
\text { expressing GUS cells for each combination of factors. }\end{array}$ \\
\hline
\end{tabular}

\section{Introduction}

Rose is the king of flowers and Damask rose (Rosa damascena Mill.) is classified in old garden roses (Peter, 1990). The origin of Damask rose is Iran and the Middle East region and it is the national flower of Iran. The major use of Damask rose is distillation of petals in order to extract its essential oil and producing rosewater. The common ways in propagating Damask rose are cutting and using suckers. The roses of Al-Taif are well known with their deep and intensive fragrance in the Arabian region. These oil rich, 30-petal rose has been cultivated in Taif for three centuries. Taif city is characterized with its favorable temperatures (as West of the Taif city rises above 2000 meters over the see level), plentiful groundwater, well established irrigation systems and fine topsoil. These advantages have combined to earn the region the name of "Arabia's Rose," ever since roses began to be cultivated there in the Ottoman era. Taif-roses have an important role in the national economy for their great value in exportation of their oil to the Arab countries, 
ornamentation, medicinal use as well as manufacture of perfumes (Bazaid, 2004).

\section{In vitro micropropagation of rose plant}

Roses are generally multiplied vegetatively by grafting buds on stem of wild rose and by cuttings. This conventional method of propagation is very slow. Moreover, disease and environmental hazards make the cultivar degenerate gradually. So, this conventional process is not satisfactory in multiplication of Rosa spp (Gamborg et al., 1995). Tissue culture methods have been developed as a potential tool for rapid and mass propagation in number of plant species. In vitro propagation of rose has played a very important role in rapid multiplication of cultivars with desirable traits and production of healthy and disease-free plants. Micropropagation offers not only quick propagation of plants, but also eliminates diseases and provides scope for development of new cultivars (Debergh et al., 1991).

A new approach to improvement by somatic hybridization is now possible with the recent success in regeneration from protoplasts. Regeneration from somatic embryos was first reported by (Souq et al., 1996) from calli of leaf, filaments and stamens. Subsequently, it was also reported from calli of leaf; filaments and immature seeds (Kunitake et al., 1993).

The genetic control of the transition to flowering in Arabidopsis has been shown to be complex, as indicated by the large number of genes known to affect this process. These allelic variants have been classified physiologically on the basis of their responsiveness to environmental factors such as day length, light quality, and vernalization. Based on this phenotypic analyses and the genetic epistasis among these mutations, flowering time genes have been grouped into several signal transduction pathways. These transmit either the developmental or environmental signals that regulate the expression of the floral meristem identity genes controlling the formation of the floral meristem (Simpson et al., 1999). The models for initiation of flowering that have been established include a photoperiod promotion pathway that promotes flowering under longday (LD) conditions, an autonomous promotion pathway that promotes flowering independently of the effect of photoperiod, and a vernalization promotion pathway that promotes flowering at low temperatures.

The photoperiod promotion pathway, also called the LD promotion pathway (Koornneef Koornneef et al., 1998), relates photoperiodic timing signals to the floral initiation process. Mutations in genes in this pathway reduce the responsiveness to photoperiod and delay the flowering of Arabidopsis plants grown in LD but do not substantially alter the flowering time of plants grown in short days SDs. Mutations in genes such as FWA, PHYA (PHYTOCHROME A, and CRY2 (CRYPTOCHROME 2, belong to this class. Cryptochromes (cry1 and cry2) are blue light (BL) photoreceptors, and it has been suggested that cry2 is the predominant photoreceptor in perception of the LD photoperiod signal in the control of flowering (15). This is based on the observation that cry2 mutants (and the allelic photoperiodinsensitive flowering time mutants fha1) flower significantly later than WT in LD but not in SD (Guo et al., 1998). A lesser role for cry1 has been proposed on evidence that some cry1 _ hy4 mutants are only slightly late flowering in SD and extended LD. In addition to induced mutants, a naturally occurring allele of CRY2 also has been identified in an accession from Cape Verde Islands (Cvi). Plants carrying this variant (originally designated EDI for Early Day length Insensitive) in a Landsberg erecta (Ler) genetic background flower early in both LD 
and SD and become day length insensitive, molecular analyses of the CRY2-Cvi allele have shown that it is a gain-of-function allele, which in SD conditions maintains a high level of CRY2 protein for a longer time after the onset of the light period than the CRY2-Ler allele (El-Assal et al., 2001). This protein stability in SD correlates with early flowering in SD and, therefore, day length insensitivity. In addition to the crys, other photoreceptors also play a role in the control of flowering. Mutants deficient in the far-red light sensor phytochrome A (phyA) are late flowering under certain LD conditions and, thus, resemble mutants of the photoperiod promotion pathway. In contrast, a deficiency in the major red light sensor phytochrome B (phyB) leads to early flowering, indicating that phyB inhibits flowering. However, because phyB mutants are still delayed in flowering by SD, phyB does not appear to act specifically in day length perception.

\section{Genetic transformation of rose}

Rose is one of the most economically important flowers worldwide. Genetic improvement of rose through conventional breeding is limited by several factors such as polyploidy and the highly heterozygous nature of existing cultivars. Genetic engineering, based on tissue culture technology, provides an option for overcoming some of these restrictions.

There are only a few published reports on Agrobacterium-mediated (Firoozabady et al., 1994; van der Salm et al., 1996) and bombardment mediated transformation in roses. Firooz abady et al., (1994) reported successful transformation of Rosa hybrida cv. Royalty following cocultivation of friable embryogenic callus with Agrobacterium tumefaciens strain LBA4404. Subsequent reports are of transformation of rose by cocultivation with A. tumefaciens strain GV3101 containing an nptII gene and rol gene from A. rhizogenes using roots derived from stem sections of the rootstock $\mathrm{R}$. hybrida cv. Moneyway. Grafting onto the transformed rootstock resulted in stimulation of both root development of rootstock and axillary-bud release of the transformed scion.

\section{Materials and Methods}

Establishment of regeneration system of Rosa hybrida L. cv. Al-Taif Rose plant

The stem nods of the Taif-Rose genotype Hada were used for the development of micropropagation system. Nodal explants containing lateral buds of actively field grown were cut and sterilized with $0.1 \%$ solution of mercuric chloride for $10 \mathrm{~min}$. The disinfected explants were inoculated aseptically on culture medium (Murashige et al., 1962) supplemented with different concentration of 2,4, D (1.0 to $4.0 \mathrm{mg} \mathrm{L-1})$ singly or in combination with Kinetin (1 mg L-1). The $\mathrm{pH}$ of medium was adjusted to 5.7 and solidified by $0.6 \mathrm{~g} \mathrm{~L}-1$ gelan gum. It was autoclaved at $121^{\circ} \mathrm{C}$ and pressure of $1 \mathrm{~kg} / \mathrm{cm} 2$ for $20 \mathrm{~min}$. For subsequent subcultures, BAP (1.0 to 4.0 mg L-1) were added to the basal medium for induction of multiple shoots. Each treatment was consisted of 3 replications in which 10 to 12 explants were used. The LSD analysis was performed using the Analyse-it software LTD (PO box 77, Leeds, LS125XA, UK) according to Maxwell and Delaney (24). All cultures were grown under a photoperiod of $16 \mathrm{~h}$ light from white fluorescent tubes at a temperature of $25 \pm 1^{\circ} \mathrm{C}$.

\section{Media}

The constitution of different MS medium used in the study is as the following:

\section{Co-cultivation medium}

MS basal medium (Murashige \& Skooge 1962) sublimated with $2 \mathrm{mg} / \mathrm{l} \mathrm{BAP}$ and $1 \mathrm{mg} / \mathrm{l}$ $\mathrm{Kn}$. 
Shoot multiplication medium MS basal medium sublimated with shoot multiplication with $3 \mathrm{mg} / \mathrm{l} \mathrm{BAP}$ and $1 \mathrm{mg} / \mathrm{l} \mathrm{Kn}$,

Shoot elongation medium shoot elongation in the presence of $1 \mathrm{mg} / \mathrm{l} \mathrm{BAP}$ and $1 \mathrm{mg} / \mathrm{K} \mathrm{Kn}$

Rooting medium a rooting stage with $2 \mathrm{mg} / \mathrm{l}$ IBA.

Establishment of transformation system of Rosa hybrida L. cv. Al-Taif Rose plant

\section{Agrobacterium-mediated transformation}

Agrobacterium tumefaciens strain harboring the plasmid pBII21, carrying the uidA gene, coding for $\beta$ - glucuronidase (GUS), and neomycin phosphotransferase (npt II) genes, coding for kanamycin, was used for transformation of rose tissues at different stages of differentiation, including leaf explant, undifferentiated callus, and embryogenic callus. The bacterial culture was established in $1 \mathrm{ml} \mathrm{LB}$ liquid medium for 12 $\mathrm{h}$, and transferred to a $50 \mathrm{ml}$ YEP (10 g 1-1 Bacto-peptone, 10 g 1-1 Bacto-yeast extract, 10 g 1-1 NaCl, pH 7.0) liquid medium containing $100 \mathrm{mg} \mathrm{l-1}$ kanamycin for another $12 \mathrm{~h}$ at $28{ }^{\circ} \mathrm{C}$.

The bacterial suspension culture was centrifuged for $10 \mathrm{~min}$ at $2240 \times \mathrm{g}$, and the pellet was dissolved in liquid shoot regeneration medium, corresponding to the different types of tissues studied. For transformation, 30 leaf explants were injured with a scalpel, while 30 uninjured calli, and 30 embryogenic calli were first separated into small clumps, and injured with a home-made multi-prong needle tool. All explants were immersed in the bacterial suspension at OD600 $=0.2$ for $30 \mathrm{~min}$. Explants were then blotted onto a sterilized filter paper, and co cultivated with Agrobacterium for $48 \mathrm{~h}$ in a regeneration medium corresponding to the

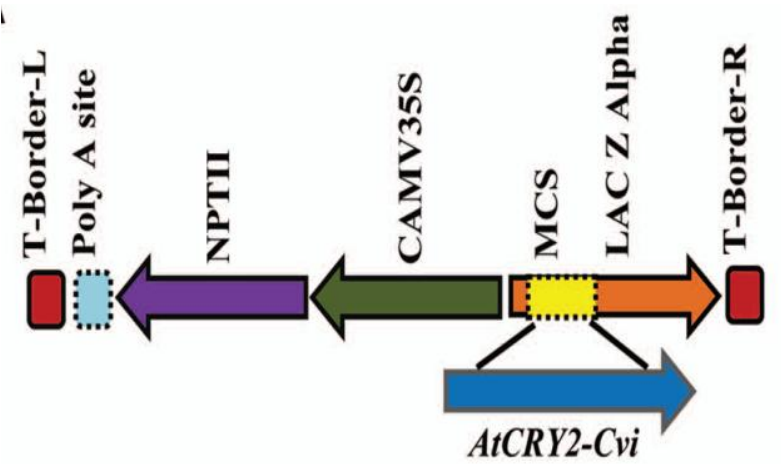

different types of tissues as described above.

The transformation vector harboring the Arabidopsis thaliana natural early flowering time allele ("Cvi" Cape Verdi Isla

\section{Evaluation of transformed plant materials}

\section{GUS histochemical analysis}

Assay for the glucuronidase (GUS) activity using 5-bromo-4-chloro-3-indoyl glucuronide (X-Glu) as a substrate was carried out as described by Jefferson, 1987. The assay culture was incubated overnight at $37{ }^{\circ} \mathrm{C}$. GUS stained explants were soaked in $70 \%$ ethanol for $24 \mathrm{~h}$.

\section{Results and Discussion}

Establishment of regeneration system of Rosa hybrida L. cv. Al-Taif Rose plant

After four weeks of culture, nodal segment explants showed different responses in production and development of multiple shoots when cultured on Murashige and Skoog medium with different concentrations of 2,4, D and kiniten. Among the various phytohormones concentrations and combinations used in this study, a combination of $1 \mathrm{mg} \mathrm{L}-1$ 2,4,D and $1 \mathrm{mg} \mathrm{L}-1$ kinetin was found to be the best to yield the highest frequency of proliferation of axillary buds and formation of axillary shoots. 
Fig.1 DNA fragment in transgenic rose plant (280 bp) in 1-4 line

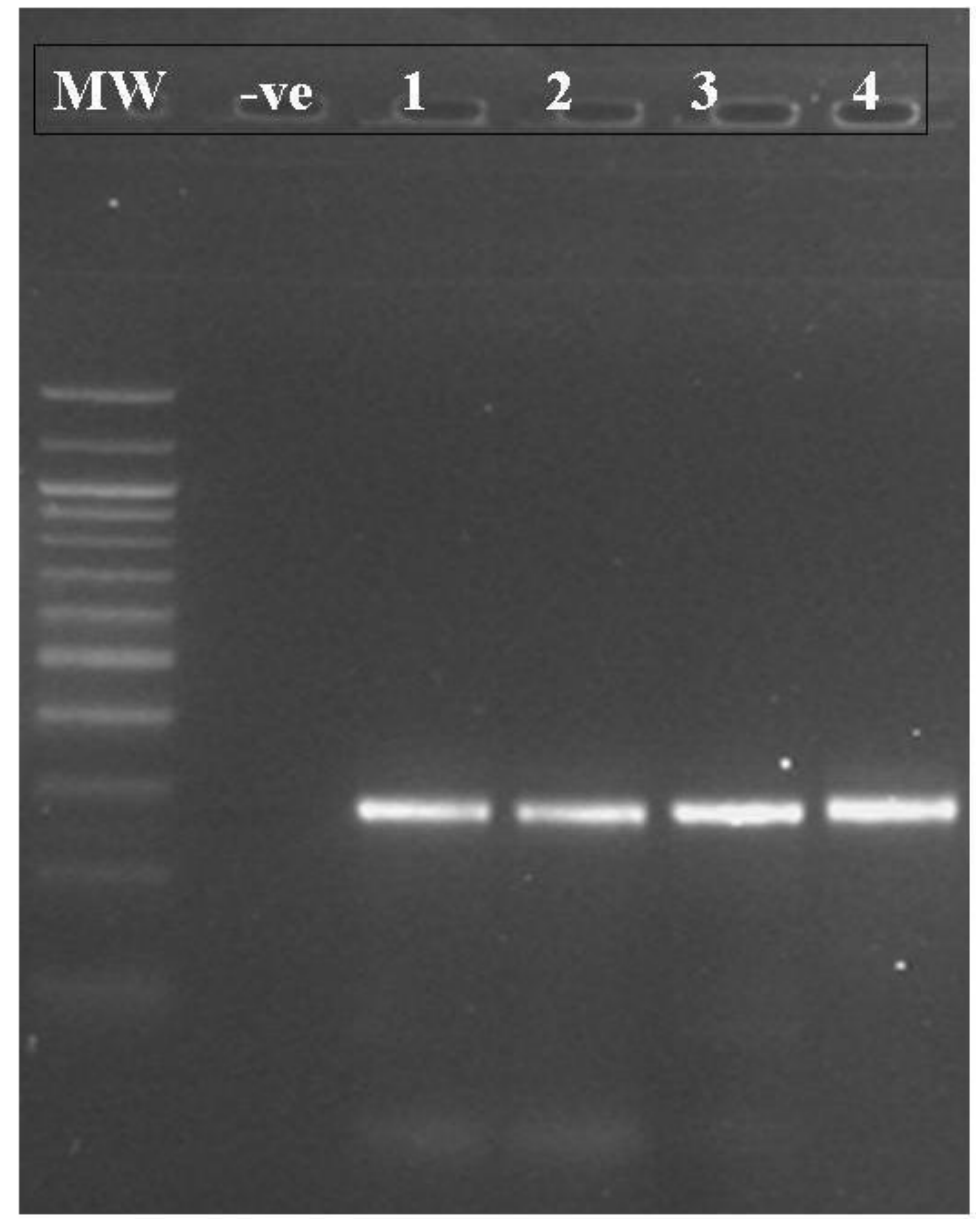

Rose transgenic lines. ( $\mathrm{MW}$ ) is a $1 \mathrm{~kb}$ ladder, (-ve) is a non transgenic line, (1-4) are different transgenic rose lines. 
While the concentration of $1 \mathrm{mg} \mathrm{L}-1$ of BAP was found to be the best to yield the highest number of multiple shoots. The maximum length of shoots was also obtained using the same concentration. The multiple shoots were obtained after 2 months and the highest number of multiple shoots per explant recorded.

\section{Transformation}

Kanamycin-resistant callus was induced from leaf explants after 1 month of incubation on a selection medium. Calli showed GUS activity as demonstrated by blue staining of the tissue. After these calli were transferred to a basal medium containing $2.3 \mu \mathrm{M}$ TDZ and $2.9 \mu \mathrm{M}$ GA3 for 2 months, embryogenic callus was not observed. When undifferentiated callus was used for transformation, $100 \%$ of callus showed GUS activity following histochemical staining; however, following further subculture, no embryogenic callus was induced.

The GUS-positive shoot regenerants were verified for the presence of both uidA and npt II genes by PCR, Since there was only a single Sst I restriction site present outside of the uidA coding sequence, digestion of transgenic plant genomic DNA and probing with the uidA coding sequence provided an estimate of the minimum number of transgenic copies present in transgenic rose lines with DNA fragment (280 bp), a single copy of the uidA transgene was integrated into the rose genome (Fig. 1).

Generally, plant transformation can be carried out using tissues at various stages of differentiation. In this study, we describe an efficient method for developing an Agrobacterium-mediated transformation system for rose. To our knowledge, this is advanced report on developing a transformation protocol for rose using a secondary somatic embryogenesis system. All transgenic plants obtained in this study have been confirmed by GUS assay.

Cryptochromes are photolyase-like proteins that regulate photomorphogenic development in plants and the circadian clock in plants and animals (26-29). Arabidopsis cryptochrome 1 (CRY1) and cryptochrome 2 (CRY2) mediate light stimulation of de-etiolation and photoperiodic control of floral initiation (Lin et al., 1998).

The method of in planta transformation was first described for Arabidopsis thaliana by Feldman and Marks (Feldman et al., 1987). In the meantime various protocols have been developed, which enable the production of thousands of independent transgenic lines within several months (reviewed by Bent). Although numerous efforts have been made to adapt the in planta transformation method to plant species other than Arabidopsis, successful protocols have only been published for a handful of different species. Detailed studies on the mechanism of in planta transformation of Arabidopsis with GUS (Int) as target gene revealed, that ovules are the primary target of transformation (Desfeux et al., 2000; Ye et al., 1999). Although reproducible GUS-expression of pollen cells was detected, the transgene was only transmitted in crosses using infiltrated plants as the pollen recipient, but not as the pollen donor.

Therefore, the expression of a transgene in germ cells does not guarantee its stable transmission in crosses. In running experiments the infiltrated plants are used in crossing experiments. As a result of reduced male and female fertility only $70 \%$ of the pollinated flowers formed hips, at present, the hips are grown to maturity. The resulting seeds will be harvested, sawn and analysed for GUS-expression. 


\section{References}

Ahmad, M., Cashmore, A.R. 1993. HY4 gene of A. thaliana encodes a protein with characteristics of a blue-light photoreceptor. Nature, 366: 162-166.

Alonso-Blanco, C., El-Assal, S.E.D., Coupland, G., Koornneef, M. 1998. Analysis of natural allelic variation at flowering time loci in the Landsberg erecta and Cape Verde Islands ecotypes of Arabidopsis thaliana. Genetics, 149: 749-764.

Bagnall, D.J., King, R.W., Hangarter, R.P. 1996. Blue-light promotion of flowering is absent in hy4 mutants of Arabidopsis. Planta, 200: 278-280.

Bazaid, S.A. 2004. Protein and DNA fragments variation in relation to low temperature in four Rosa hybirida cultivars in Taif, Saudi Arabia. $J$. Egypt. Acad. Dev., 5: 77-90.

Bent, A.F. 2000. Arabidopsis in planta transformation. Uses, mechanism, and prospects for transformation of other species. Plant Physiol., 124: 15401547.

Cashmore, A.R. 2003. Cryptochromes: Enabling plants and animals to determine circadian time. Cell, 114: 537-543.

Chaves, I., et al. 2011. The cryptochromes: Blue light photoreceptors in plants and animals. Annu Rev. Plant Biol., 62: 335-364.

Debergh, P.C. and P.E. Read. 1991. Micropropagation. pp. 1-13. In: Micropropagation: Technology and Application. (Ed.): P.C. Debergh and R.H. Zimmerman. Kluwer Acad. Publishers, London.

Desfeux, C., Clough, S.J., and Bent, A.F. 2000. Female reproductive tissues are the primary target of Agrobacteriummediated transformation by floral-dip method. Plant Physiol., 123: 895-904.
El-Assal, S.E.D., Alonso-Blanco, C., Peeters, A.J.M., Raz, V., Koornneef, M. 2001. A QTL for flowering time in Arabidopsis reveals a novel allele of CRY2. Nat. Genet., 29: 435-440.

Feldman, K.A., and Marks, M.D. 1987. Agrobacterium-mediated transformation of germinating seeds of Arabidopsis thaliana: a non-tissue culture approach. Mol. Gen. Genet., 208: 1-9.

Firoozabady, E., Moy, Y., CourtneyGutterson, N., Robinson, K. Regeneration of transgenic rose (Rosa hybrida) plants from embryogenic tissue. BioTechnol., 12: 609-613.

Gamborg, O.L. and Phillips, G.C. 1995. Laboratory facilities, operation and management. In: Fundamental Methods of Plant Cell, Tissue and Organ Culture, OL Gamborg and GC Phillips (Eds.), Springer-Verlag, Berlin, pp. 3-20.

Guo, H., Yang, H., Mockler, T.C., Lin, C. 1998. Regulation of flowering time by Arabidopsis photoreceptors. Sci., 279: 1360-1363.

Guo, H., Yang, H., Mockler, T.C., Lin, C. 1998. Regulation of flowering time by Arabidopsis photoreceptors. Sci., 279:1360-1363.

Jefferson, R.A. 1987. Assaying chimeric genes in plants: the GUS gene fusion system, Plant Mol. Biol. Reptr., 5: 387-405.

Johnson, E., Bradley, M., Harberd, N.P., Whitelam, G.C. 1994. Photoresponses of light-grown phyA mutants of Arabidopsis. Plant Physiol., 105: 141149.

Koornneef, M., Alonso-Blanco, C., Peeters, A.J.M., Soppe, W. 1998. Genetic control of flowering time in Arabidopsis. Annu Rev. Plant Physiol. Plant Mol. Biol., 49: 345-370.

Koornneef, M., Hanhart, C., van Loenen- 
Martinet, P., Blankestijn-de Vries, H. 1995. The effect of daylength on the transition to flowering in phytochrome-deficient, late-flowering and double mutants of Arabidopsis thaliana. Physiol Plant, 95: 260-266.

Kunitake, H., Imamizo, H., Mii, M. 1993. Somatic embryogenesis and plant regeneration from immature seedderived calli of rugosa rose (Rosa rugosa Thunb.). Plant Sci., 90:187194.

Lin, C., et al. 1998. Enhancement of bluelight sensitivity of Arabidopsis seedlings by a blue light receptor cryptochrome 2. Proc. Natl. Acad. Sci., USA, 95: 2686-2690.

Matthews, D., Mottley, J., Yokoya, K. and A.V. Roberts. 1994. Regeneration of plants from protoplasts of Rosa species. In: Bajaj, Y.P.S. (Ed.): Biotechnology in Agriculture and Forestry 29, Plant Protoplasts and Genetic Engineering V. SpringerVerlag Berlin, Heidelberg, 146-160.

Maxwell, S.E. and H.D. Delaney, 1989. Designing Experiments and Analyzing Data. 1st Edn., Wadsworth, Belmont, CA, pp: 260.

Mouradov, A., Cremer, F., Coupland, G. 2002. Control of flowering time: interacting pathways as a basis for diversity. Plant Cell, 14: S111-S130.

Murashige, T. and F. Skoog, 1962. A revised medium for rapid growth and bio assays with tobacco tissue cultures. Physiol. Plantarum, 15: 473-497.

DOI:10.1111/j.13993054.1962.tb08052.x.

Noriega, C. and M.R. Sondahl, 1991. Somatic embryogenesis in hybrid tea roses.

Biotechnol., 9: 991-993.

Peter Bealis, T. 1990. Botanica Roses. Grange
Books PLC, London-England.

Rout, G.R., Samantaray, S., Mottley, J., Das, P. 1999. Biotechnology of the rose: a review of recent progress. Sci. Hort., 81:201-228.

Sancar, A. 2003. Structure and function of DNA photolyase and cryptochrome bluelight photoreceptors. Chem. Rev., 103: 2203-2237.

Simpson, G.G., Gendall, A.R., Dean, C. 1999. When to switch to flowering. Annu Rev. Cell Dev. Biol., 99: 519-550.

Soppe, W.J.J., Jacobsen, S.E., Alonso-Blanco, C., Jackson, J.P., Kakutani, T., Koornneef, M., Peeters, A.J.M. 2000. The late flowering phenotype of fwa mutant is caused by gain-of-function epigenetic alleles of a homeodomain gene. Mol Cell, 6: 791-802.

Souq, F., Coutos-Thevenot, P., Yean, H., Delbard, G., Maziere, Y., Barber, J.P. 1996. Genetic transformation of roses, 2 examples: one on morphogenesis, the other on anthocyanin biosynthetic pathway. Second Intl. Symp. Roses, Acta Hortic., 424: 381-388.

van der Salm, T.P.M., van der Toorn, C. J. G., Bouwer, R., Hanisch ten Cate, C. H., Dons, H.J.M. Somatic embryogenesis and shoot regeneration from excised adventitious roots of the rootstock Rosa hybrida L. 'Moneyway'. Plant Cell Rep., 15: 522-526.

Ye, G.N., Stone, D., Pang, S.Z., Creely, W., Gonzales, K., and Hinchee, M. 1999. Arabidopsis ovule is the target for Agrobacterium in planta vacuum infiltration transformation. The Plant J., 19: 249-257.

Yu, X., Liu, H., Klejnot, J., Lin, C. 2010. The cryptochrome blue-light receptors. The Arabidopsis Book (American Society of Plant Biologists, Rockville, MD). 
How to cite this article:

Adel E.EL-Tarras, Salah El-Asaal and Ahmed shahaby. 2017. Genetic Transformation Protocol for Early Flowering Cryptochrome Gene in Taif Rose Plant. Int.J.Curr.Microbiol.App.Sci. 6(3): 2067-2075. doi: https://doi.org/10.20546/ijcmas.2017.603.236 